\section{Case Report}

Korean J Transplant 2020;34:199-203

https://doi.org/10.4285/kjt.2020.34.3.199
Received May 20, 2020

Revised June 15, 2020

Accepted June 16, 2020

Corresponding author: Jaeseok Yang Department of Surgery, Transplantation Center, Seoul National University Hospital, 101 Daehak-ro, Jongno-gu, Seoul 03080, Korea

Tel: +82-2-2072-4128

Fax: +82-2-2072-4129

E-mail: jcyjs@snu.ac.kr

(c) The Korean Society for Transplantation This is an Open Access article distributed under the terms of the Creative Commons Attribution Non-Commercial License (http://creativecommons.org/licenses/ by-nc/4.0/) which permits unrestricted non-commercial use, distribution, and reproduction in any medium, provided the original work is properly cited.

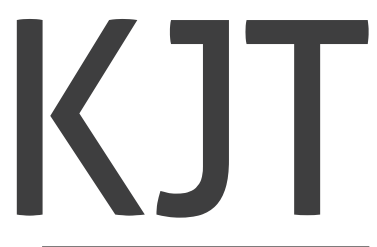

pISSN 2671-8790

eISSN 2671-8804

\title{
Recurrent parvovirus B19 infection-associated pure red cell aplasia in a kidney transplant patient
}

\author{
Sujin Gang ${ }^{1}$, Sooyong Park ${ }^{2}$, Sang-il Min ${ }^{1,3}$, Joonshik Hong ${ }^{4}$, Yoon Hwan Chang ${ }^{2}$, \\ Jongwon $\mathrm{Ha}^{1,3}$, Jaeseok Yang ${ }^{1,3,5}$ \\ ${ }^{1}$ Department of Surgery, Seoul National University Hospital, Seoul, Korea \\ ${ }^{2}$ Department of Laboratory Medicine, Seoul National University Hospital, Seoul, Korea \\ ${ }^{3}$ Transplantation Research Institute, Seoul National University College of Medicine, Seoul, Korea \\ ${ }^{4}$ Department of Internal Medicine, Seoul National University Hospital, Seoul, Korea \\ ${ }^{5}$ Transplantation Center, Seoul National University Hospital, Seoul, Korea
}

Posttransplant anemia is a common complication after kidney transplantation. Parvovirus B19 (PVB19) infection can induce pure red cell aplasia (PRCA) in immunosuppressed transplant patients. We herein report a case of recurrent PVB19-associated PRCA in a kidney transplant patient. A 49-year-old woman presented with anemia and normal renal function 1 year after a deceased-donor kidney transplantation for immunoglobulin $A$ nephropathy-related end-stage renal disease. She received desensitization therapy, and 2 years later, she underwent transplantation with thymoglobulin induction. Despite repeated red cell transfusion and erythropoietin therapy, her anemia aggravated progressively. Bone marrow biopsy revealed normocytic normochromic PRCA. Real-time polymerase chain reaction detected a high plasma load of PVB19. Administration of intravenous immunoglobulin (IVIG) at $2 \mathrm{~g} / \mathrm{kg}$ with adjuvant reduction of tacrolimus and discontinuation of myfortic acid effectively treated the anemia. However, the PVB19 load remained high, and PRCA recurred 7 months after the initial IVIG treatment. Tacrolimus was switched to cyclosporine in the second IVIG treatment, which successfully improved PRCA and reduced the PVB19 load. Our case suggested that PVB19-associated PRCA should be suspected when persistent anemia is observed in kidney transplant patients with heavy immunosuppression and that PVB19-associated PRCA can recur in the presence of persistent PVB19 viremia.

Keywords: Intravenous immunoglobulin; Kidney transplantation; Parvovirus B19 infection; Pure red cell aplasia

\section{INTRODUCTION}

Anemia frequently occurs at an early stage post-kidney transplantation $[1,2]$. Common predisposing factors for post-transplant anemia are immunosuppressive drugs and an increased risk of opportunistic infection [1]. Other contributing factors include blood loss, iron and folate deficiency, low erythropoietin, persistent hyperparathyroidism, and post-transplant medication [3]. Pure red cell aplasia (PRCA) is defined as the failure of erythropoiesis with preserved granulopoiesis and megakaryopoiesis. Patients often present with refractory normocytic nor- 


\section{HIGHLIGHTS}

- Parvovirus B19-associated pure red cell aplasia can recur in the presence of persistent PVB19 viremia in heavily immunosuppressed kidney transplant patients.

- Recurrent Parvovirus B19-associated pure red cell aplasia should be controlled by reduction of immunosuppression as well as intravenous immunoglobulin therapy.

mochromic anemia with a low reticulocyte count and, in some instances, thrombotic microangiopathy. The diagnostic criteria for PRCA are normocytic anemia with less than $0.1 \%$ reticulocytes in the peripheral blood as well as less than $5 \%$ erythroblasts, giant pronormoblasts, normal megakaryopoiesis, and granulopoiesis in the bone marrow [3]. Parvovirus B19 (PVB19) infection can cause PRCA in children and immunocompromised patients, especially in kidney transplant patients. Destruction of pronormoblasts in the bone marrow leads to persistent anemia and reticulocytopenia, which are unresponsive to erythropoietin. Thus far, only a few cases of PVB19-associated PRCA after kidney transplantation have been reported in Korea [4], and no recurrent cases have been documented. We herein report the first recurrent case of PVB19-associated PRCA in a kidney transplant patient who was successfully treated with repeated intravenous immunoglobulin (IVIG).

\section{CASE REPORT}

A 49-year-old woman presented with anemia. She had endstage renal disease due to immunoglobulin $A$ nephropathy and started continuous ambulatory peritoneal dialysis at the age of 38 . She was registered on the wait-list for deceased-donor kidney transplantation. Owing to high levels of class I panel reactive antibodies (mean fluorescence intensity, 7,229), she received desensitization involving six sessions of plasmapheresis and three doses of bortezomib $\left(1.3 \mathrm{mg} / \mathrm{m}^{2}\right)$. Two years later, she received a deceased-donor kidney transplantation with induction of thymoglobulin $(1.5 \mathrm{mg} / \mathrm{kg})$. She subsequently recovered well under maintenance immunosuppression therapy involving prednisolone, tacrolimus, and myfortic acid. She experienced two episodes of urinary tract infection during the first year after transplantation. Cytomegalovirus and BK virus were negative at the time, but her Epstein-Barr virus load was 3,820 copies $/ \mathrm{mL}$. Fourteen months after transplantation, she developed dyspnea. Her hemoglobin level was $7.4 \mathrm{~g} / \mathrm{dL}$, which was a drop from $14.0 \mathrm{~g} / \mathrm{dL}$ at 1 -year posttransplant. Serum ferritin, iron, and total iron-binding capacity were $412.7 \mathrm{ng} / \mathrm{mL}, 65 \mu \mathrm{g} / \mathrm{dL}$, and $252 \mu \mathrm{g} / \mathrm{dL}$, respectively. Her vitamin B12 level was $611 \mathrm{pg} / \mathrm{mL}$, and folate level was $3.96 \mathrm{ng} / \mathrm{mL}$. Reticulocytes decreased to $0.18 \%$. The results of direct and indirect Coombs tests were negative. Levels of plasma hemoglobin and haptoglobin were $2.4 \mathrm{mg} / \mathrm{dL}$ and $45 \mathrm{mg} / \mathrm{dL}$, respectively. There was no evidence of gastrointestinal bleeding, and stool hemoglobin level was within the normal range. Additionally, leukocyte and platelet counts were within the normal range. A peripheral blood smear showed minimal neutropenia, leftshift of neutrophils, and normocytic normochromic anemia without schistocytes. Her serum blood urea nitrogen and creatinine levels were maintained within the normal range.

One week after administration of methoxy polyethylene glycol-epoetin- $\beta$, her hemoglobin level dropped to $6.7 \mathrm{~g} / \mathrm{dL}$ while leukocyte and platelet counts remaining within the normal range. Despite discontinuation of myfortic acid, her anemia aggravated. As the anemia progressed from

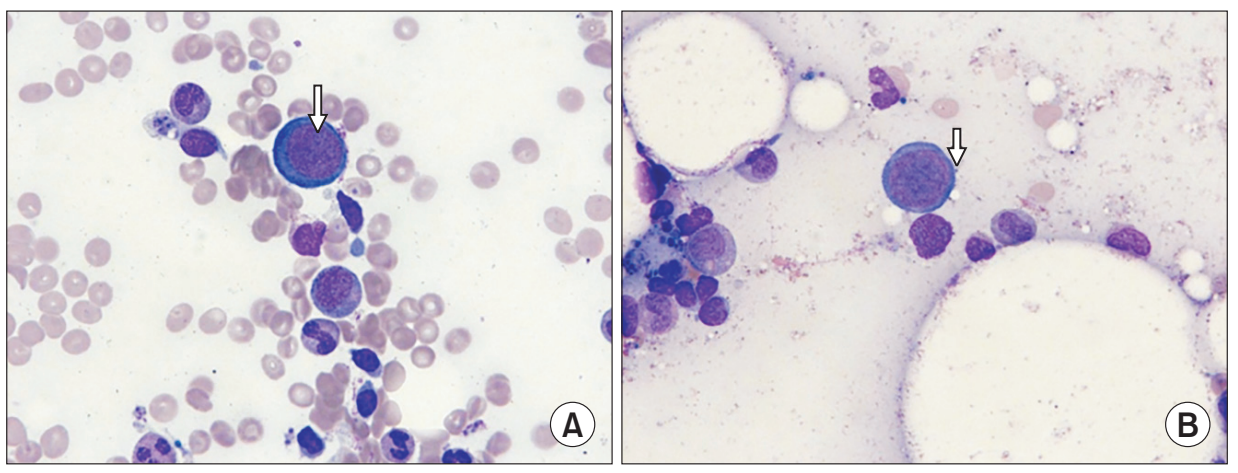

Fig. 1. Bone marrow aspiration findings. Wright-Giemsa staining $(x 1,000)$ images of bone marrow aspiration smears showing (A) giant pronormoblasts with nuclear viral inclusion bodies (nucleoli-like, eosinophilic inclusion body, arrow) and (B) giant pronormoblasts with "dog ear" cytoplasmic projections (arrow). 


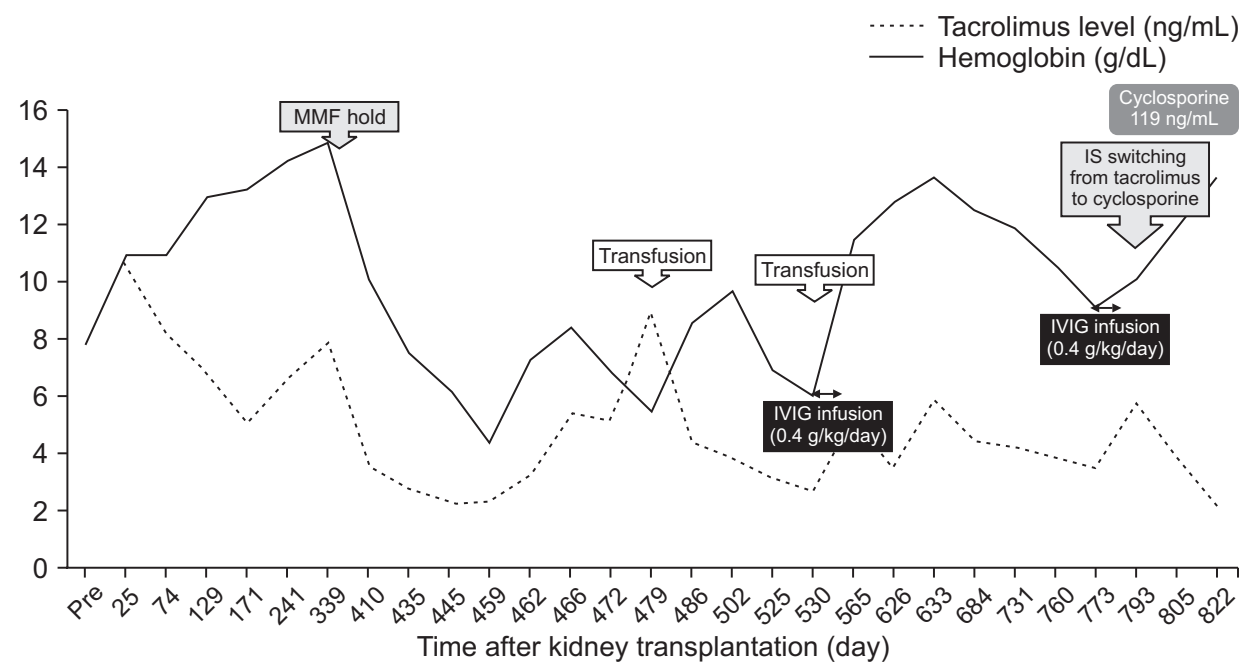

Fig. 2. Changes in blood cell count after kidney transplantation. The patient's hemoglobin level dropped from $14.0 \mathrm{~g} / \mathrm{dL}$ at 12 months posttransplant to $7.4 \mathrm{~g} / \mathrm{dL}$ at 14 months posttransplant. Despite erythropoietin treatment, anemia progressed to $4.2 \mathrm{~g} / \mathrm{dL}$, requiring two cycles of red blood cell transfusion. Intravenous immunoglobulin (IVIG) treatment initiated at 17 months posttransplant normalized her hemoglobin level at 19 months posttransplant. However, anemia recurred at 24 months posttransplant, and the second IVIG treatment initiated at 25 months Posttransplant successfully improved her anemia. IS, immunosuppressants; MMF, mycophenolate mofetil.

$6.1 \mathrm{~g} / \mathrm{dL}$ to $4.2 \mathrm{~g} / \mathrm{dL}$, she received transfusion of two units of leukocyte-depleted packed red blood cells. Her hemoglobin levels initially increased but dropped rapidly and required a second transfusion. The PVB19 load measured using quantitative real-time polymerase chain reaction (PCR) was more than $60,000,000$ copies/mL plas$\mathrm{ma}$. In the bone marrow aspiration smear, cellularity was $20 \%-40 \%$ which was normocellular for age. The estimated myeloid-to-erythroid ratio was 6.7:1. Abnormal giant pronormoblasts with nuclear viral inclusion bodies and "dog ear" cytoplasmic projections were observed (Fig. 1). The number of erythroid precursors was decreased. Despite the reduction in erythropoiesis, granulopoiesis was normal and megakaryocyte count was within the normal range (3-4/high-power field). These findings indicated a diagnosis of PVB19-induced PRCA.

IVIG therapy was administered at a dose of $0.4 \mathrm{~g} / \mathrm{kg} /$ day for 5 days. Simultaneously, the target trough blood level of tacrolimus was decreased to $4 \mathrm{ng} / \mathrm{mL}$. Reticulocyte count initially increased from $0.25 \%$ to $14.14 \%$. One week later, her hemoglobin level increased to $8.0 \mathrm{~g} / \mathrm{dL}$ without additional treatments and were normalized at $13.6 \mathrm{~g} / \mathrm{dL}$ within 2 months. No recurrence of PRCA had been reported since then, and her hemoglobin levels were maintained above $13 \mathrm{~g} / \mathrm{dL}$. However, her 7-month follow-up PVB19 viral titer was still over $50,000,000$ copies/mL plasma.

Her hemoglobin levels dropped to $11.8 \mathrm{~g} / \mathrm{dL}$ and progressed to $9.0 \mathrm{~g} / \mathrm{dL} 1$ month later (Fig. 2). Due to the absence of other indications for recurrent anemia except for the persistently high PVB19 titer, a PVB19-associated PRCA recurrence was suspected. IVIG therapy $(0.4 \mathrm{~g} / \mathrm{kg} /$ day) was restarted at 9 months after the initial IVIG therapy. Simultaneously, tacrolimus was converted to cyclosporine to alleviate immunosuppression and thereby reduce PVB19 viremia. Her hemoglobin level slowly recovered to normal and then improved to $13.2 \mathrm{~g} / \mathrm{dL} 2$ months after the second treatment. The last PVB19 load was 9,104 copies/ $\mathrm{mL}$ plasma.

\section{DISCUSSION}

PVB19 belongs to the Parvoviridae family and the genus Erythrovirus, and it is the only human pathogen of this family. It is $25 \mathrm{~nm}$-long, non-enveloped, and consists of a single-stranded linear DNA of $5 \mathrm{~kb}$ in length. It has a selective tropism for the globosides of human erythroid progenitor cells known as the erythrocyte $P$ antigen, which are expressed on the surfaces of erythroid cells, erythroid precursors, red blood cells of the placenta, fetal myocardium, fetal liver, some megakaryocytes, and endothelial cells. Productive infection is seen only in erythroid precursors, and the consequent viral replication leads to 
cytopathic effects. The incidence of PVB19 infection in anemic kidney transplant patients was reported to be $12 \%$ in a single-center study, but this has been variable among different centers [5]. Until 2000, 26 cases of PVB19-related anemia have been reported in solid organ transplant patients [6]. PVB19 infections often induce severe or persistent anemia [7], skin rash, arthropathy (fever, arthralgia, and rash) [8], pancytopenia, graft loss, or dysfunctions such as hepatitis, myocarditis, pneumonitis, neurological disease, and vasculitis in immunocompromised hosts. Anemia has been found in $99 \%$ of immunocompromised hosts with PVB19 infection and is often accompanied by an inappropriate reticulocyte response or erythropoietin resistance. PVB19 infection should be suspected early in cases of anemia in immunocompromised patients, including transplant patients, and prompt evaluation should be initiated. Viral detection in clinical specimens is important for the diagnosis of PVB19 infection. Although anti-PVB19 immunoglobulin $M$ antibody is detected in $75 \%$ of solid organ transplant patients at the time of diagnosis, the absence of antibodies in immunocompromised hosts may not exclude a PVB19 infection due to their delayed or inappropriate humoral response. Detection of PVB19 DNA in tissues is the key diagnostic approach but may also generate positive results in asymptomatic patients, which is a limitation. In situ hybridization or immunohistochemistry of the bone marrow should therefore be performed in patients with a strongly suspected diagnosis of PVB19 infection despite negative serology and PCR results.

Our patient presented with anemic symptoms such as fatigue and dyspnea and satisfied the criteria for PVB19-associated PRCA based on her elevated PVB19 viral load, bone marrow findings, and laboratory test results that suggested no other cause of anemia. Humoral immune response and neutralizing antibodies are important in controlling the progression of PVB19-associated PRCA. Patients without sufficient antibody responses are therefore susceptible to persistent PVB19 infection. Recurrent PVB19 infections have also been frequently reported in kidney transplant patients with heavy immunosuppression; for example, patients who receive thymoglobulin as induction therapy.

IVIG is the mainstay therapy for PVB19-associated PRCA, and it is a widely used regimen, with a total dose of 2 $\mathrm{g} / \mathrm{kg}$ over 2 to 5 days, although the daily dose and duration of therapy may vary according to centers. However, a daily dose of more than $1 \mathrm{~g} / \mathrm{kg}$ with a shorter course increases the risk of nephrotoxicity and other side effects [9]. There has been no difference in the relapse rate between a total dose of more than $2 \mathrm{~g} / \mathrm{kg}$ and that of less than $2 \mathrm{~g} / \mathrm{kg}$ [10]. Cidofovir was reported to affect the inhibition of viral replication in vitro [11]. Importantly, adjuvant reduction of immunosuppressive therapy should be considered for PVB19-associated PRCA [2]. Regular follow-up monitoring of viral PVB19 DNA is not effective due to the persistence of viremia despite an appropriate therapeutic response. Quantitative real-time PCR for PVB19 should instead be considered. While additional IVIG therapy is indicated for relapsed anemia, no evidence has supported the preemptive use of IVIG for preventing recurrence of PVB19-associated PRCA.

Initially, IVIG at a dose of $2 \mathrm{~g} / \mathrm{kg}$ was administered for 5 days with adjuvant reduction of maintenance immunosuppression, including discontinuation of myfortic acid and dose reduction of tacrolimus. Despite so, her PVB19 viral load remained high. In parallel with her history of pre-transplant desensitization and thymoglobulin induction, a high risk of PRCA recurrence was indicated. Seven months after the initial IVIG therapy, anemia without a definite cause other than an elevated PVB19 viremia occurred, which strongly suggested recurrent PVB19-associated PRCA. A second therapy of IVIG successfully improved her anemia. In addition, tacrolimus was converted to cyclosporine to reduce the risk of re-recurrence, and PVB19 titer was indeed reduced after conversion. This finding was in line with that of a previous report that tacrolimus is an independent risk factor for PVB19 infection [12]. In the previously reported recurrent case of PVB19-associated PRCA, tacrolimus was switched to cyclosporine at the lower limit of the target blood level, and a successful outcome was achieved upon completion of IVIG therapy [13]. Another study on two patients reported favorable outcomes after single therapy of IVIG for recurring PRCA [14].

Thus far, the direct effects of tacrolimus on PVB19 have not been documented. Although the role of cellular immunity against PVB19 infection is unclear, PVB19-specific $C D 8^{+} T$ cell responses have been detected [15]. This suggests the potential contribution of tacrolimus to the suppression of T-cell immunity, which is usually involved in the humoral immunity against PVB19.

Thus far, only a few cases of PVB19-associated PRCA have been reported in kidney transplant patients in Korea [4]. While their diagnosis was made according to qualitative PCR results, we utilized quantitative real-time PCR, which is a more advanced diagnostic tool. Similar IVIG regimens were used, which were associated with initial improvement of PRCA. However, we report the first case 
of recurrent PVB19-associated PRCA in a Korean kidney transplant patient, suggesting that PVB19 infection is an important cause of recurrent posttransplant anemia in kidney transplant patients with heavy immunosuppression. Patients with persistent PVB19 viremia and a history of PVB19-associated PRCA therefore require careful monitoring for PRCA recurrence.

\section{ACKNOWLEDGMENTS}

\section{Conflict of Interest}

No potential conflict of interest relevant to this article was reported.

\section{Funding/Support}

This study was supported by research grant from the Korean Society for Transplantation (2020-03-02002-008).

\section{ORCID}

Sujin Gang Sooyong Park Sang-il Min Joonshik Hong Yoon Hwan Chang Jongwon $\mathrm{Ha}$ Jaeseok Yang

https://orcid.org/0000-0003-1765-9437 https://orcid.org/0000-0002-4424-4467 https://orcid.org/0000-0002-0688-0278 https://orcid.org/0000-0002-7829-397X https://orcid.org/0000-0002-9010-5281 https://orcid.org/0000-0003-2285-3517 https://orcid.org/0000-0002-5378-7797

\section{Author Contributions}

Conceptualization: JY. Data curation: SIM, JH, JH. Formal analysis: SG. Funding acquisition: JY. Methodology: YHC, JY. Visualization: SP. Writing-original draft: SG. Writingreview \& editing: JY.

\section{REFERENCES}

1. Vanrenterghem Y. Anaemia after renal transplantation. Nephrol Dial Transplant 2004;19 Suppl 5:V54-8.

2. Yorgin PD, Scandling JD, Belson A, Sanchez J, Alexander SR, Andreoni KA. Late post-transplant anemia in adult renal transplant recipients: an under-recognized problem? Am J Transplant 2002;2:429-35.

3. Pabisiak K, Stępniewska J, Ciechanowski K. Pure red cell aplasia after kidney transplantation: parvovirus B19 culprit or coincidence? Ann Transplant 2019;24:123-31.

4. Choi SH, Chang SP, Won JC, Lee JS, Chi HS, Yang WS, et al. A case of persistent anemia in a renal transplant recipient: association with parvovirus B19 infection. Scand J Infect Dis 2002;34:71-5.

5. Ki CS, Kim IS, Kim JW, Lee NY, Kim SH, Lee KW, et al. Incidence and clinical significance of human parvovirus B19 infection in kidney transplant recipients. Clin Transplant 2005;19:751-5.

6. Geetha D, Zachary JB, Baldado HM, Kronz JD, Kraus ES. Pure red cell aplasia caused by Parvovirus B19 infection in solid organ transplant recipients: a case report and review of literature. Clin Transplant 2000;14:586-91.

7. Rao KR, Patel AR, Anderson MJ, Hodgson J, Jones SE, Pattison JR. Infection with parvovirus-like virus and aplastic crisis in chronic hemolytic anemia. Ann Intern Med 1983;98:930-2.

8. Ager EA, Chin TD, Poland JD. Epidemic erythema infectiosum. N Engl J Med 1966;275:1326-31.

9. Crabol Y, Terrier B, Rozenberg F, Pestre V, Legendre C, Hermine $\mathrm{O}$, et al. Intravenous immunoglobulin therapy for pure red cell aplasia related to human parvovirus b19 infection: a retrospective study of 10 patients and review of the literature. Clin Infect Dis 2013;56:968-77.

10. Eid AJ, Brown RA, Patel R, Razonable RR. Parvovirus B19 infection after transplantation: a review of 98 cases. Clin Infect Dis 2006;43:40-8.

11. Bonvicini F, Bua G, Manaresi E, Gallinella G. Antiviral effect of cidofovir on parvovirus B19 replication. Antiviral Res 2015;113:11-8.

12. Baek $\mathrm{CH}$, Kim H, Yang WS, Han DJ, Park SK. Risk factors and long-term outcomes of parvovirus B19 infection in kidney transplant patients. Transpl Infect Dis 2017;19:e12754.

13. Kaya B, Paydas S. Recurrence of pure red cell aplasia in a kidney transplant recipient due to reactivation of parvovirus B19 infection despite two cycles of intravenous immunoglobulin therapy. Exp Clin Transplant 2019;17(Suppl 1):195-7.

14. Pinto V, Grandy J, Zambrano P, Corta B, Salas P, Salgado $I$, et al. Severe anemia from parvovirus b19 infection in pediatric renal transplant recipients: two case reports. Transplant Proc 2008;40:3261-4.

15. Eid AJ, Chen SF; AST Infectious Diseases Community of Practice. Human parvovirus B19 in solid organ transplantation. Am J Transplant 2013;13 Suppl 4:201-5. 